\title{
Social Transmission and Buffering of Hippocampal Metaplasticity after Stress in Mice
}

\author{
I-Chen Lee, ${ }^{1}$ Ting-Hsuan Yu, ${ }^{2}$ Wen-Hsin Liu, ${ }^{3}$ and ${ }^{\circledR}$ Kuei-Sen Hsu ${ }^{1,2}$ \\ ${ }^{1}$ Department of Pharmacology, National Cheng Kung University, Tainan 70101, Taiwan, ${ }^{2}$ Institute of Basic Medical Sciences, College of Medicine, \\ National Cheng Kung University, Tainan 70101, Taiwan, and ${ }^{3}$ Department of Family Medicine, Ditmanson Medical Foundation Chia-Yi Christian \\ Hospital, Chiayi 60002, Taiwan
}

In social animals, the behavioral and hormonal responses to stress can be transmitted from one individual to another through a social transmission process, and, conversely, social support ameliorates stress responses, a phenomenon referred to as social buffering. Metaplasticity represents activity-dependent synaptic changes that modulate the ability to elicit subsequent synaptic plasticity. Authentic stress can induce hippocampal metaplasticity, but whether transmitted stress has the same ability remains unknown. Here, using an acute restraint-tailshock stress paradigm, we report that both authentic and transmitted stress in adult male mice trigger metaplastic facilitation of long-term depression (LTD) induction at hippocampal CA1 synapses. Using LTD as a readout of persistent synaptic consequences of stress, our findings demonstrate that, in a malemale dyad, stress transmission happens in nearly half of naive partners and stress buffering occurs in approximately half of male stressed mice that closely interact with naive partners. By using a social-confrontation tube test to assess the dominantsubordinate relationship in a male-male dyad, we found that stressed subordinate mice are not buffered by naive dominant partners and that stress transmission is exhibited in $\sim 60 \%$ of dominant naive partners. Furthermore, the appearance of stress transmission correlates with more time spent in sniffing the anogenital area of stressed mice, and the appearance of stress buffering correlates with more time engaged in allogrooming from naive partners. Chemical ablation of the olfactory epithelium with dichlobenil or physical separation between social contacts diminishes stress transmission. Together, our data demonstrate that transmitted stress can elicit metaplastic facilitation of LTD induction as authentic stress.

Key words: corticosterone; hippocampus; long-term depression (LTD); metaplasticity; social buffering; social transmission

\section{Significance Statement}

Social animals can acquire information about their environment through interactions with conspecifics. Stress can induce enduring changes in neural activity and synaptic function. Current studies are already unraveling the transmission and buffering of stress responses between individuals, but little is known about the relevant synaptic changes associated with social transmission and buffering of stress. Here, we show that authentic and transmitted stress can prime glutamatergic synapses onto hippocampal CA1 neurons to undergo long-term depression. This hippocampal metaplasticity is bufferable following social interactions with naive partners. Hierarchical status of naive partners strongly affects the social buffering effect on synaptic consequences of stress. This work provides novel insights into the conceptual framework for synaptic changes with social transmission and buffering of stress.

Received July 7, 2020; revised Nov. 16, 2020; accepted Nov. 30, 2020.

Author contributions: I.-C.L., T.-H.Y., W.-H.L., and K.-S.H. designed research; I.-C.L. and T.-H.Y. performed

research; I.-C.L. and T.-H.Y. analyzed data; I.-C.L., T.-H.Y., W.-H.L., and K.-S.H. wrote the paper.

The authors declare no competing financial interests.

This work was supported by research grants from the National Health Research Institute (Grant NHRIEX109-10912NI) and the Ministry of Science and Technology (Grants 107-2320-B-006-037-MY3 and 108-2331B-006-025-MY2), Taiwan.

Correspondence should be addressed to Kuei-Sen Hsu at richard@mail.ncku.edu.tw or Wen-Hsin Liu at cych04574@gmail.com.

https://doi.org/10.1523/JNEUROSCI.1751-20.2020

Copyright $\odot 2021$ the authors

\section{Introduction}

Social species, such as humans, primates, and rodents, are born with a rich repertoire of behavioral expressions that enable the transmission of affect to other members of the group (Monfils and Agee, 2019). From an evolutionary perspective, the ability to transmit information from an affected individual to naive partners is critical to the species survival, as it can promote intergroup cooperation and alert group members to potential threats in the environment, without direct exposure to the sources of danger (de Waal and Preston, 2017). Recent studies demonstrate that exposure to a stressed partner can trigger stress-related 
adaptations through the processes known as social transmission (contagion) or social buffering (Bruchey et al., 2010; Smith and Wang, 2014; Martin et al., 2015; Burkett et al., 2016; Sterley et al., 2018). Classically, social transmission refers to the process whereby a stressed individual transmits stress-related information to naive partners by social interactions. In contrast, in the case of social buffering, distressed individuals benefit from conspecific consolation behaviors during or after distressing events. These two social processes are functionally antagonistic but may rely on shared neurobehavioral mechanisms related to social information use in treat detection (Oliveira and Faustino, 2017). These social interactions are crucial for stress coping in social communities, but their underlying neurobiological mechanisms have remained elusive.

Despite the extensive evidence that implicates behavioral, physiological, and hormonal changes in partners of stressed individuals (Bruchey et al., 2010; Martin et al., 2015; Burkett et al., 2016), few studies have directly interrogated the synaptic changes associated with social transmission and buffering after stress. While a recent report demonstrated that both authentic and transmitted stress primed glutamatergic synapses onto corticotropin-releasing hormone $(\mathrm{CRH})$ neurons in the paraventricular nucleus of the hypothalamus (PVN) to undergo short-term potentiation (STP) in response to high-frequency afferent stimulation (Sterley et al., 2018), whether transmitted stress has similar synaptic actions more broadly in other brain regions is not known. Importantly, stress is known to alter the ability to induce subsequent synaptic plasticity, a phenomenon called metaplasticity, particularly in the hippocampus (Kim and Diamond, 2002; Huang et al., 2005; Schmidt et al., 2013). We and others have reported previously that, in the CA1 region of the hippocampus, a brief experience of acute inescapable stress can impair high-frequency stimulation-induced long-term potentiation (Diamond et al., 1992; Kim et al., 1996; Shors et al., 1997; Yang et al., 2004, 2006), whereas the induction of long-term depression (LTD) by prolonged low-frequency stimulation (LFS) is facilitated (Kim et al., 1996; Xu et al., 1997; Yang et al., 2004, 2005). Stress-induced hippocampal metaplasticity may therefore represent an ideal model with which to assay the synaptic aspect of social transmission and the buffering of stress effects. In this study, we report that the priming of hippocampal CA1 synapses in response to either authentic or transmitted stress facilitates the induction of LTD. Our findings also indicate that transmitted stress from stressed subjects to naive partners is through direct social contacts and probably requires the release of alarm pheromones. The presence of naive partners can provide a social-buffering effect on stressed subjects. Hierarchical status of naive partners strongly affects the effectiveness of social buffering. Remarkably, stressed subordinate subjects are not buffered by naive dominant partners. These findings represent a further step toward understanding the synaptic consequences of social transmission and buffering after stress.

\section{Materials and Methods}

Animals. Adult male C57BL/6 mice (8-10 weeks of age) were originally obtained from Charles River Laboratories but were bred in the Laboratory Animal Center at National Cheng Kung University. Mice were socially housed four per cage in a $12 \mathrm{~h}$ (lights on at 6:00 A.M.) light/dark colony room at $25 \pm 1^{\circ} \mathrm{C}$, and all experiments were conducted during the light phase of the cycle. Mice had access to food and water ad libitum, except during stress and social interaction tests. Experiments were conducted blind to the treatment group and in compliance with the guidelines of the National Institutes of Health Guide for the Care and
Use of Laboratory Animals, under protocols approved by the Institutional Animal Care and Use Committee at National Cheng Kung University. All efforts were made to minimize animal suffering and the number of animals used.

Acute stress protocol and social interaction assessment. One week before the experiments, mice were housed in groups of two per cage. Age- and weight-matched mouse pairs were randomly assigned to receive the stress treatment or left naive. An acute unpredictable and inescapable restraint-tailshock stress paradigm was used as described previously (Chen et al., 2010; Hsiao et al., 2016). In the experiment, one mouse out of the pair was removed from the home cage and was restrained in a modified $50 \mathrm{ml}$ centrifuge tube and exposed to 90 tailshocks ( $1 \mathrm{~mA}$ for $1 \mathrm{~s}, 30-90 \mathrm{~s}$ apart). We selected this stress protocol because it has been proven previously to reliably induce behavioral and endocrine signs of stress (Kim et al., 1996; Yang et al., 2004). Naive mice received no treatment and remained in the home cage. The stressed mouse was held alone after the end of the stress protocol. Mice in the nonstressed group were handled like those of the stress group, except that they were not submitted to the restraint-tailshock procedure, the mice being kept alone in their home cage instead. Reciprocal social interaction between pairs of mice in the home cage was videotaped for $30 \mathrm{~min}$ and tracked with the EthoVision XT video tracking systems (Noldus; RRID:SCR_000441). In some experiments, a perforated Plexiglas barrier was inserted to physically separate mice to prevent direct contact. The following 11 behaviors were manually scored: approach, social grooming (allogrooming), chasing, sniffing, attacking, walking, self-grooming, digging, rearing, resting, and nesting (Sterley et al., 2018).

Social dominance tube test. The tube test was conducted as described previously (Wang et al., 2011). Pairs of male mice were matched for age, body weight, and anxiety-like behavior in the open-field test. It used a transparent acrylic tube (length, $30 \mathrm{~cm}$; internal diameter, $3 \mathrm{~cm}$ ), which is sufficient enough to permit one adult mouse to pass through without reversing its direction. For training, each mouse was released at alternating ends of the tube and ran through the tube. When the mouse retreated or stopped moving for a certain period of time, it was gently pushed by touching its back with a plastic stick. Each mouse was given in eight training trials on each of 2 successive days. Social ranks were evaluated with three trials per day for 3 consecutive days. During the test trial, two mice were released simultaneously into the opposite ends and care was taken to ensure that they met in the middle of the tube. The mouse that first retreated from the tube within 2 min was designated the "loser" of that trial. The tube was thoroughly cleaned with $70 \%$ ethanol and dried between each trial. From trial to trial, the mice were released from each end alternatively. The intertrial interval was $5 \mathrm{~min}$. We used winning times as the index for dividing mice into the dominant and subordinate categories. A mouse winning at least two times in three trials across 3 consecutive days was declared the dominant mouse, and the paired mouse was declared the subordinate mouse.

Olfactory preference test. An olfactory preference test was conducted to assess olfactory function as previously described (Kobayakawa et al., 2007). Mice were individually placed into a clean plastic cage $(37.5 \times$ $17 \times 18 \mathrm{~cm}$ ) without bedding and were habituated to the cage for $15 \mathrm{~min}$ before the test. In the test session, mice were exposed to distilled water or peanut buffer in sequence, separated by a $10 \mathrm{~min}$ intertrial interval. One hundred microliters of distilled water or peanut butter (10\%) was applied onto an opaque filter paper $(3 \times 3 \mathrm{~cm})$ and attached to a random corner in the cage. On each test trial, one odor was exposed to $3 \mathrm{~min}$. The mouse was allowed to freely explore the field and recorded using a digital video camera, and scoring was performed with the EthoVision $\mathrm{XT}$ video tracking systems. To analyze olfactory performance, the total exploratory time spent with the peanut butter subtracted from the time spent with water was calculated. The chamber was thoroughly cleaned with $70 \%$ ethanol following each trial to remove any residual olfactory traces.

Hippocampal slice preparations and electrophysiological recordings. Hippocampal slices were prepared as previously described (Chen et al., 2010; Hsiao et al., 2016). Immediately after a $30 \mathrm{~min}$ social interaction, mice were anesthetized with isoflurane (Rhodia Organique Fine Ltd) 
A

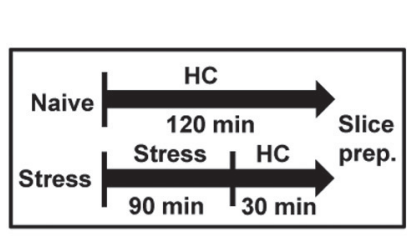

B

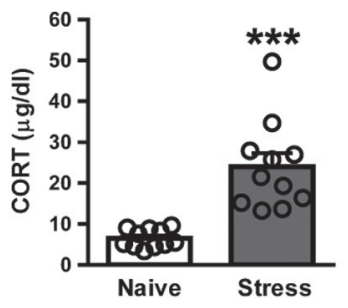

C

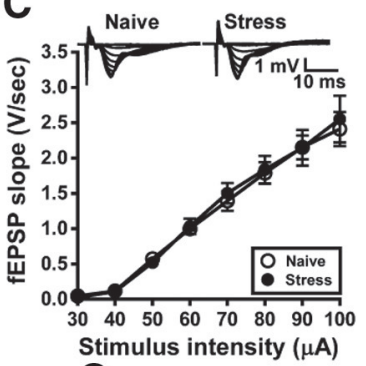

G
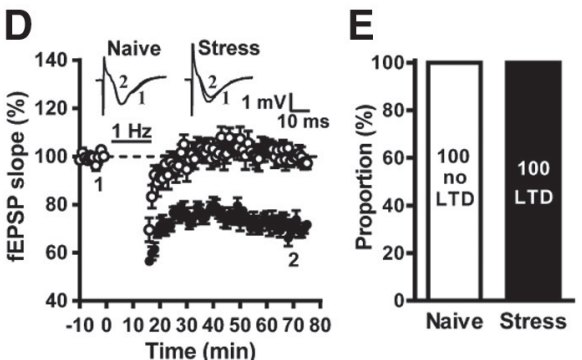

$\mathbf{F}$

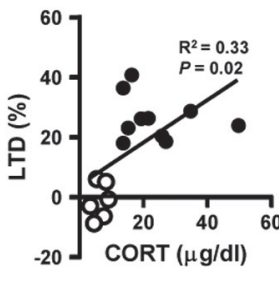

Figure 1. Acute stress facilitates the induction of LTD in the CA1 region of the hippocampus. $A$, Schematic showing the experimental design and timeline. Naive mice remained in the home cage (HC) for $120 \mathrm{~min}$. The stressed mice were exposed to an inescapable restraint-tailshock stress for $60 \mathrm{~min}$, and then were kept alone in their home cage for 30 min before slice preparation. $\boldsymbol{B}$, Bar graph comparing serum corticosterone levels in naive male mice and stressed male mice. $\boldsymbol{C}$, Input-output curve of fEPSP $(\mathrm{V} / \mathrm{s})$ versus stimulus intensity $(\mu \mathrm{A})$ at Schaffer collateral-CA1 synapses in slices from naive and stressed male mice. $\boldsymbol{D}$, Summary of experiments showing the induction of hippocampal CA1 LTD by a prolonged LFS (1 Hz for $15 \mathrm{~min}$ ) at Schaffer collateral-CA1 synapses in slices from naive and stressed male mice. $\boldsymbol{E}$, Bar graph illustrating the proportion of individuals that express LTD or no LTD in naive and stressed groups. $\boldsymbol{F}$, A significant positive linear correlation is evident between the serum corticosterone levels and LTD expression. $G$, Bar graphs comparing the average magnitudes of LTD in slices from naive and stressed male mice at different time points $(0.5-24 \mathrm{~h})$ after the termination of stress. The magnitudes of LTD were measured at 50-60 min after LFS. Representative traces of fEPSPs were taken at the time indicated by number. Dash lines show the level of baseline. Data represent the mean \pm SEM. Numbers in parentheses represent animals examined. $* p<0.05$ and $* * * p<0.001$ compared with naive mice by two-tailed unpaired Student's $t$ test or Bonferroni's post hoc test.

and decapitated, and hippocampal slices $(400 \mu \mathrm{m})$ were prepared using a vibrating blade microtome (model VT1000S, Leica Biosystems). The slices were placed in a holding chamber of artificial CSF (aCSF) containing the following (in mM): $117 \mathrm{NaCl}, 4.7 \mathrm{KCl}, 2.5 \mathrm{CaCl}_{2}, 1.2 \mathrm{MgCl}_{2}, 25$ $\mathrm{NaHCO}_{3}, 1.2 \mathrm{NaH}_{2} \mathrm{PO}_{4}$, and 11 glucose at $\mathrm{pH}$ 7.3-7.4 and equilibrated with $95 \% \mathrm{O}_{2}-5 \% \mathrm{CO}_{2}$ then maintained at room temperature for at least $1 \mathrm{~h}$ before use.

For recordings, one slice was transferred to a submersion-type recording chamber and continuously perfused with oxygenated aCSF at a flow rate of $2-3 \mathrm{ml} / \mathrm{min}$ at $\sim 32^{\circ} \mathrm{C}$ on a fixed stage. The extracellular field potential recordings were conducted using an Axoclamp-2B amplifier (Molecular Devices). Microelectrodes were pulled from microfibercontaining glass capillary tubing (outer diameter, $1.0 \mathrm{~mm}$ ) on a Brown-Flaming electrode puller (Sutter Instruments) and were filled with $1 \mathrm{~m} \mathrm{NaCl}$. The responses were low-pass filtered at $2 \mathrm{kHz}$, digitally sampled at $10 \mathrm{kHz}$ (Digidata 1320A, Molecular Devices), and analyzed with pCLAMP 8.0 software (Molecular Devices). Field EPSPs (fEPSPs) were evoked in CA1 stratum radiatum by extracellular stimulation of Schaffer collateral/commissural afferents at $0.033 \mathrm{~Hz}$ using a bipolar tungsten stimulating electrode. The stimulation strength was adjusted to elicit a response having amplitude that was $30 \%$ $40 \%$ of the maximum spike-free response. The slope of fEPSP was measured from $\sim 20-70 \%$ of the rising phase using the least-squares regression. LTD was induced by 900 pulses delivered at $1 \mathrm{~Hz}$. The magnitude of LTD was calculated as percentage of the change of fEPSP slope 50-60 min after LTD induction compared with baseline fEPSP (10 min before LTD induction). LTD was defined as being present when the fEPSP slope displayed $>10 \%$ decrease in magnitude of its baseline value.

Chemical ablation of the olfactory epithelium. To chemically ablate the olfactory epithelium, mice were subjected to intraperitoneal injection of a single dose of dichlobenil (2,6-dichlobenzonitrile; $150 \mathrm{mg} / \mathrm{kg}$ body weight; Sigma-Aldrich) dissolved in DMSO as previously described (Lazarini et al., 2012). The levels of chemical lesion in the main olfactory epithelium tissues were evaluated based on the expression of olfactory marker protein (OMP) within the glomerular layer of the olfactory bulb (OB). For immunofluorescence staining, mice were deeply anesthetized with $5 \%$ isoflurane and transcardially perfused with ice-cold 0.1 м PBS followed by buffered $4 \%$ paraformaldehyde (PFA). After the perfusion, isolated brains were immersed in $4 \%$ PFA for $24 \mathrm{~h}$ at $4^{\circ}$ $\mathrm{C}$ and then immersed in the solution containing $30 \%$ sucrose, kept at $4^{\circ} \mathrm{C}$ for at least $48 \mathrm{~h}$ before slicing. Coronal slices were sectioned to a $20 \mu \mathrm{m}$ thickness, and rinsed twice for $5 \mathrm{~min}$ at $25^{\circ} \mathrm{C}$ in $0.1 \mathrm{M}$. Na borate, $\mathrm{pH} 8.5$, and then incubated in the primary antibodies against OMP (1:300, rabbit monoclonal IgG; catalog \#ab183948, Abcam) with background-reducing components (catalog \#S3022, DAKO) overnight at $4^{\circ} \mathrm{C}$, followed by an incubation with the Alexa Fluor-conjugated secondary antibody for $2 \mathrm{~h}$ at room temperature. The nuclei were visualized using DAPI (1:5000; Sigma-Aldrich) staining. Fluorescence microscopic images of neurons were obtained using an confocal microscope (FluoView FV1000, Olympus). All images were imported into NIH ImageJ software (RRID:SCR_001935) for analysis, and all the parameters used were kept consistent during capturing.

Adrenalectomy and corticosterone replacement. Adrenalectomy (ADX) was performed through bilateral dorsal incisions under isoflurane anesthesia as previously described (Chen et al., 2010; Hsiao et al., 2016). ADX mice received corticosterone replacement $(10 \mu \mathrm{g} / \mathrm{ml}$ in $0.9 \%$ saline) via their drinking water immediately after surgery. Corticosterone was first dissolved in $100 \%$ ethanol and then diluted 1000 times in drinking water containing $0.9 \%$ saline. Mice were used for experiments for at least 2 weeks after surgery. Control mice underwent a sham surgery by using the identical procedure as the ADX mice, except that the adrenal glands were not removed. Successful ADX was verified by measurement of the serum corticosterone levels. Only mice with baseline serum corticosterone concentrations $<1 \mu \mathrm{g} / \mathrm{dl}$ were considered successful and were used in the subsequent experiments.

Corticosterone assay. Trunk blood was collected immediately after decapitation with anesthesia into an Eppendorf tube and allowed to coagulate at $4^{\circ} \mathrm{C}$ for $1 \mathrm{~h}$. Samples were centrifuged at $2000 \times g$ at $4^{\circ} \mathrm{C}$ for $15 \mathrm{~min}$, and serum was aliquoted and frozen at $-20^{\circ} \mathrm{C}$ until analysis. Determination of corticosterone level in serum was performed using a commercially available enzyme immunoassay kit (catalog \#ADI-900097, Enzo Life Sciences; RRID:AB_2307314) according to the manufacturer instructions. All assays were performed in duplicate, and average values were reported.

Hippocampal cannula implantation and drug injection. Mice were bilaterally implanted under deep pentobarbital $(50 \mathrm{mg} / \mathrm{kg}$, i.p., supplemented as required) anesthesia with 28 gauge guide cannulas (Plastics One) in the dorsal hippocampus as previously described (Tsai et al., 2019). Coordinates for mice were $-2.3 \mathrm{~mm}$ posterior to bregma, \pm 1.5 $\mathrm{mm}$ bilateral to midline, and $1.8 \mathrm{~mm}$ ventral to brain surface according to adult mouse brain stereotaxic atlas (Franklin and Paxinos, 2008). The cannulas were fixed to the skull with dental cement. Dummy cannulas (33 gauge) were inserted into each guide cannula following the surgery to prevent clogging. Mice were allowed to recover from surgery for 2 weeks before cannula infusion and stress experiments. The NMDA receptor antagonist aminophosphonovalerate (APV; $3.2 \mu \mathrm{g}$ ) was bilaterally 
administered into the hippocampus at the rate of $0.25 \mu \mathrm{l} / \mathrm{min}(0.5 \mu \mathrm{l} / \mathrm{side}) 20 \mathrm{~min}$ before stress exposure by using a 33 gauge needle that connected via polyethylene tubing to a Hamilton syringe. APV was dissolved in PBS. Drug dose was selected on the basis of published study (Stiedl et al., 2000). The infusion cannulas were kept in place for an additional 2 min to minimize backflow of the injectant. Histologic verification of the cannula locations was performed at the end of experiments.

Statistical analysis. No statistical methods were used to predetermine sample size, but sample size choice was based on previous work of a similar nature by our laboratory (Chen et al., 2010; Hsiao et al., 2016). The results are presented as the mean \pm SEM. All statistical analyses were performed using the GraphPad Prism 6 software (RRID:SCR_002798). To compare the difference between the two population mean values, we first determined whether the data were normally distributed using the Shapiro-Wilk test. The significance of any difference between two groups was calculated using the paired or unpaired two-tailed Student's $t$ test. One-way or two-way repeatedmeasures ANOVAs were used for comparison of multiple groups, and Bonferroni's post hoc analyses were applied to assess the significance between groups. LTD magnitudes across multiple slices from the same animal were averaged to yield a single value for each animal. Because the data of LTD magnitudes were not normally distributed, the Mann-Whitney $U$ test was used to compare differences between two independent groups. $N$ represents the number of animals used. Differences were considered as significant at $p<0.05$.

\section{Results}

Acute stress induces metaplasticity of LTD at Schaffer collateral-

\section{CA1synapses}

Subjecting adult male mice to acute stress (Fig. 1A) significantly increased serum corticosterone levels compared with naive controls (naive controls: $6.5 \pm 0.7$ $\mu \mathrm{g} / \mathrm{dl} ; n=11$; stressed mice: $24.0 \pm 3.3$ $\mu \mathrm{g} / \mathrm{dl} ; n=11 ; t_{(20)}=5.23, p<0.001$, two-tailed unpaired Student's $t$ test; Fig.

$1 B)$, confirming that our experimental restraint-tailshock stressor activates hypothalamus-pituitary-adrenal responses as described previously (Yang et al., 2005; Hsiao et al., 2016). To examine the effect of stress on the induction of LTD at Schaffer collateral-CA1 synapses, we performed extracellular fEPSP recordings in ex vivo hippocampal slices from naive and stressed mice. To determine whether the basal glutamatergic synaptic transmission was altered by stress, stimulusresponse relationships for fEPSPs obtained from naive and stressed mice were compared. As shown in Figure 1C, stimulus-response curves of fEPSPs were not significantly different between slices from mice 30 min after stress $(n=4)$ and naive treatment $\left(n=3, F_{(8,45)}=0.05, p=0.99\right.$; two-way ANOVA). To assess stress-related alterations in LTD induction, we chose a prolonged LFS ( $1 \mathrm{~Hz}$ for $15 \mathrm{~min}$ ) protocol, which failed to induce significant LTD at Schaffer collateral-
B
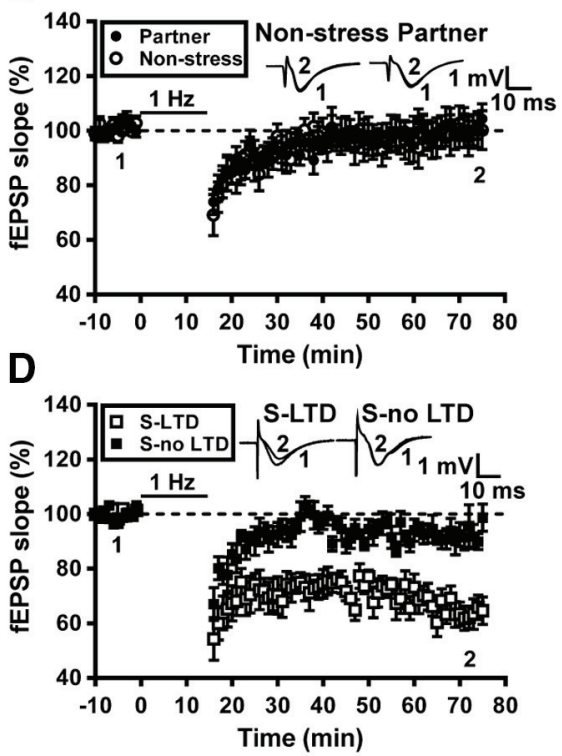

F

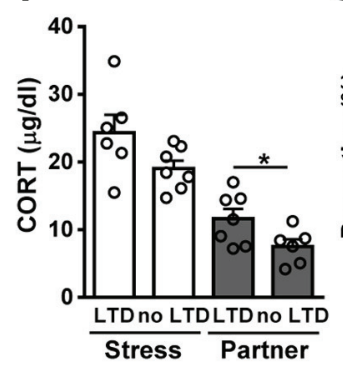

G

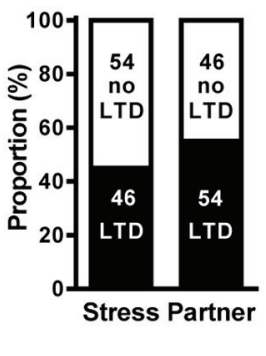

Figure 2. Transmission and buffering of metaplastic LTD following social interactions with a familiar conspecific. $\boldsymbol{A}$, schematic showing the experimental design and timeline. Male adult mice were housed in pairs for at least 1 week. In the experiment, the subject mouse was removed, exposed to a restraint-tailshock stress paradigm for $90 \mathrm{~min}$, and then returned stressed male mice and naive male partners. C S Summary of experiments showing the grand mean LTD magnitudes at Schaffer collateral-CA1 synapses in slices from stressed male mice and naive male partners. $\boldsymbol{D}$, Summary of experiments showing the induction of hippocampal CA1 LTD by LFS at Schaffer collateral-CA1 synapses in slices from stressed male mice. $\boldsymbol{E}$, Summary of experiments showing the induction of hippocampal CA1 LTD by LFS at Schaffer collateral-CA1 synapses in sli-

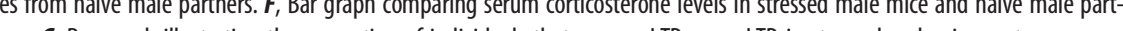
resent the mean \pm SEM. $* p<0.05$ compared with no LTD partner mice by two-tailed unpaired Student's $t$ test.

CA1 synapses in hippocampal slices from adult mice under control conditions (Milner et al., 2004; Khoo et al., 2019). In accordance with previous results (Yang et al., 2005; Hsiao et al., 2016), when LTD was assessed 50 min after the end of LFS, slices from stressed male mice exhibited a robust LTD $(28.7 \pm$ $2.6 \%, n=12)$ compared with slices from naive controls (1.8 \pm $2.4 \%, n=6, p=0.001$; Mann-Whitney $U$ test; Fig. $1 D)$. Our observations demonstrate that LTD occurred in 100\% of slices from stressed male mice and no LTD occurred in $100 \%$ slices from naive controls (Fig. $1 E$ ). In addition, akin to the results of adult male rats (Yang et al., 2004), there was a significant positive linear correlation between the levels of serum corticosterone and LTD expression $(p=0.02$; Fig. $1 F)$. To verify how long the effect of stress persists, hippocampal slices were prepared at different time points after stress, and then LTD was examined. The facilitation of LTD by stress was significantly observed in slices from 0.5 to $12 \mathrm{~h}$ post-stress intervals, but not in slices from $24 \mathrm{~h}$ post-stress interval (naive, $n=6 ; 0.5 \mathrm{~h}$, 
A

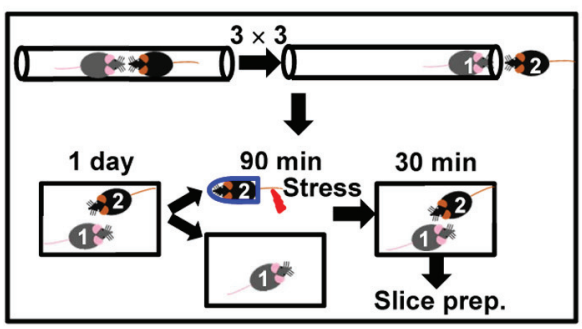

B

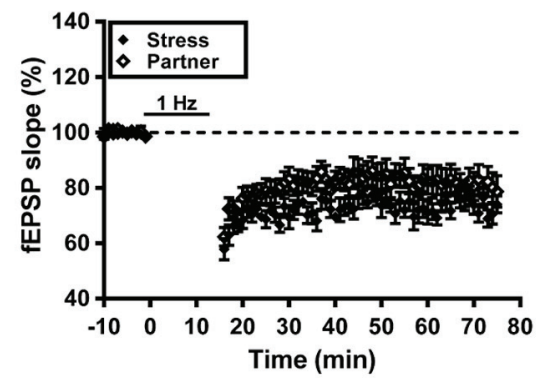

C

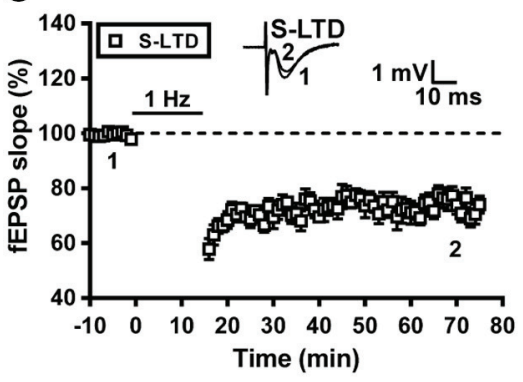

D

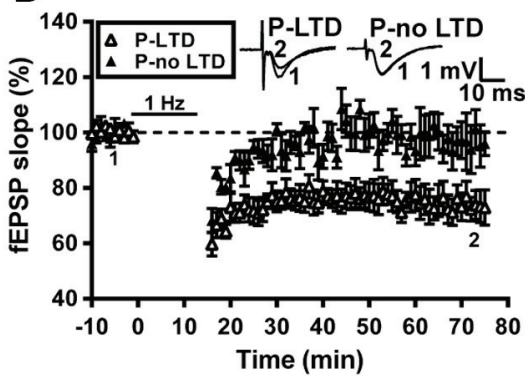

examine social transmission and buffering of stress-induced metaplasticity.

Transmission and buffering of stressinduced metaplasticity following social interactions

Using the metaplastic facilitation of LTD as a readout of the enduring synaptic consequence of stress, we conducted experiments to determine the effect of social interactions on stress-induced hippocampal metaplasticity. To this end, male adult mice were housed in pairs for at least 1 week before the start of the experiment. In the experiment, the subject mouse was removed, exposed to an unpredictable and inescapable restraint-tailshock stress paradigm for $90 \mathrm{~min}$, and then returned to its home cage and allowed to freely interact with the partner for $30 \mathrm{~min}$ (Fig. 2A). Following social interactions, mice were killed and hippocampal slices were prepared for examining LTD induction. In control experiments, we observed no significant LTD in slices from either nonstressed subjects $(5.2 \pm 5.7 \%, n=3)$ or naive partners $(0.7 \pm 2.6 \%, n=3 ; p=0.94$, Mann-Whitney $U$ test; Fig. 2B). However, LTD was successfully induced in slices from both stressed subjects $(20.6 \pm 4.9 \%$, $n=13)$ and naive partners (16.5 $\pm 5.0 \%$, $n=13$ ). When comparing the grand mean LTD magnitudes, no significant difference was observed between groups $(p=0.57$, Mann-Whitney $U$ test; Fig. $2 C$ ). Notably, a significant difference in the grand mean LTD magnitude was observed between naive controls (Fig. $1 D$ ) and nonstressed naive partners $(p=0.03$; Mann-Whitney $U$ test; Fig. 2C). Across the population $(n=13)$, we observed that a subpopulation of stressed subjects $(n=6 / 13)$ displayed obvious LTD, whereas a subpopulation of stressed subjects $(n=7 / 13)$ showed no LTD (Fig. 2D). In addition, we found that LTD was evident in slices from $54 \%(n=7 /$ 13) of naive partners (Fig. 2E). Although there was a trend toward a decrease in the levels of serum corticosterone in no LTD-

$n=12 ; 3 \mathrm{~h}, n=3 ; 12 \mathrm{~h}, n=3 ; 24 \mathrm{~h}, n=3 ; F_{(4,22)}=2.18, p<0.001$, one-way ANOVA; Fig. $1 G$ ). We further explored whether sex differences exist in the facilitatory effect of stress on LTD induction. We observed no LTD in slices from either stressed (4.8 \pm $2.8 \%, n=4)$ or naive $(1.0 \pm 2.7 \%, n=3, p=0.25$; MannWhitney $U$ test; data not shown) female mice. However, akin to the results from adult male mice, serum corticosterone levels were significantly higher in stressed female mice than in naive female mice (naïve controls: $4.7 \pm 1.0 \mu \mathrm{g} / \mathrm{dl}, n=3$; stressed mice: $22.8 \pm 5.9 \mu \mathrm{g} / \mathrm{dl}, n=4 ; t_{(5)}=2.61, p=0.04$, twotailed unpaired Student's $t$ test; data not shown). Collectively, these results suggest that acute stress can prime hippocampal CA1 glutamatergic synapses to undergo LTD in adult male mice, but not in adult female mice, similar to reports in rats (Yang et al., 2005; Huang et al., 2012). Therefore, only male mice were used to expressing stressed mice, the difference did not achieve statistical significance when compared with LTD-expressing stressed mice (LTD, $n=6$; no LTD, $n=7 ; t_{(11)}=1.94, p=0.08$, two-tailed unpaired Student's $t$ test; Fig. 2F). However, a significant increase in serum corticosterone level was observed in LTD-expressing naive partners when compared with no LTD-expressing naive partners (LTD, $n=7$; no LTD, $n=6 ; t_{(11)}=2.21, p=0.04$, twotailed unpaired Student's $t$ test; Fig. 2F). These findings support the notion that stress can be transmitted from a stressed subject to a naive partner through social interactions, and naive partners can provide social buffering to the stressed subjects. Our observations demonstrate that, in a male-male dyad, stress transmission happened in nearly $54 \%$ of naive partners and stress buffering occurred in $\sim 54 \%$ of stressed mice (Fig. $2 G$ ). 
Hierarchical status affects transmission and buffering of stressinduced metaplasticity following social interactions

Given that hierarchical status greatly influences social interactions and vulnerability to stress (Wang et al., 2014; Larrieu et al., 2017; Williamson et al., 2017; Kunkel and Wang, 2018), we wondered whether preexisting dominance hierarchies may affect the vulnerability to social transmission or buffering of hippocampal metaplasticity after stress. To this end, we applied a social confrontation tube test, a reliable paradigm to measure dominant behavior in rodents (Wang et al., 2011), to validate social dominance in male mice housed in pairs. In the first experiments, a subordinate mouse was subjected to stress and a dominant mouse was assigned as naive partner (Fig. 3A). Following social interactions, we found that LTD was reliably induced in slices from both stressed subordinate mice and dominant naive partners. When comparing the grand mean LTD magnitudes, no significant difference was observed between stressed subordinate mice $(26.1 \pm 3.1 \%, n=10)$ and dominant naive partners $(21.3 \pm 4.5 \%$, $n=10 ; p=0.25$; Mann-Whitney $U$ test; Fig. $3 B$ ). Across the population, we found that LTD was reliably induced in slices from all stressed subordinate mice $(n=10$; Fig. $3 C)$ and $60 \%(n=6 / 10)$ of dominant naive partners (Fig. 3D). The levels of corticosterone were significantly higher in LTD-expressing dominant naive partners than no LTD-expressing dominant naive partners (LTD, $n=6$; no LTD, $n=4 ; t_{(8)}=2.65, p=0.03$, two-tailed unpaired Student's $t$ test; Fig. $3 E$ ). Using LTD induction as a metaplastic readout, our observations demonstrate that stress transmission happened in nearly $60 \%$ of dominant naive partners, and no stress buffering occurred in stressed subordinate mice (Fig. $3 F$ ).

In complementary experiments, dominant mice were subjected to stress and subordinate mice were assigned as naive partners (Fig. 4A). Following social interactions, we found that LTD was reliably induced in slices from both stressed dominant mice and subordinate naive partners. When comparing the grand mean LTD magnitudes, no significant difference was observed between stressed dominant mice $(22.7 \pm 8.0 \%, n=11)$ and subordinate naive partners $(10.8 \pm 4.1 \%, n=11 ; p=0.22$; MannWhitney $U$ test; Fig. $4 B$ ). Across the population, we found that dominant mice subjected to stress can be separated into two subpopulations, one of which $(n=5 / 11)$ displayed obvious LTD and the other $(n=6 / 11)$ showed no LTD (Fig. $4 C)$. In addition, we found that LTD was evident in slices from $45 \%(n=5 / 11)$ subordinate naive partners (Fig. $4 D$ ). The levels of corticosterone were not significantly different between LTD- and no LTD-expressing
B

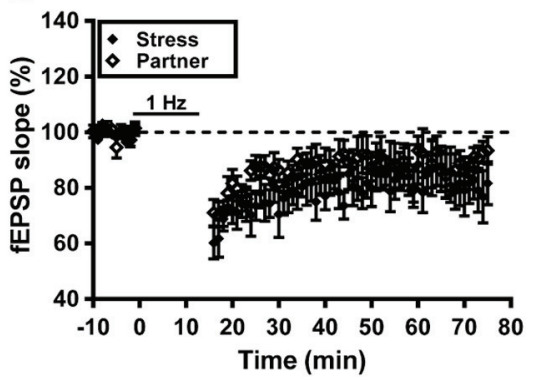

D

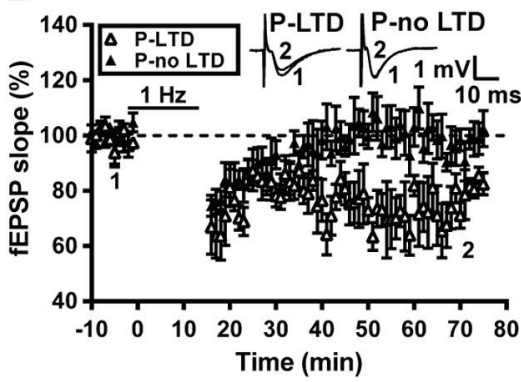

$E$

Figure 4. Hierarchical status does not alter the transmission of metaplastic LTD following social interactions with a conspecific. $\boldsymbol{A}$, Cartoon of mice engaged in the social confrontation tube test. Schematic showing the experimental design and time(hank 1) mouse was subjected to a restraint-tailshock stress paradigm for 90 min, and then

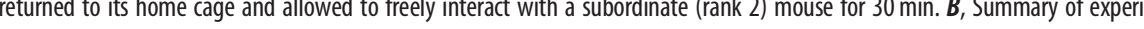
me grand mean LTD magnitudes at Schaffer collateral-CA1 synapses in slices from stressed dominant mice

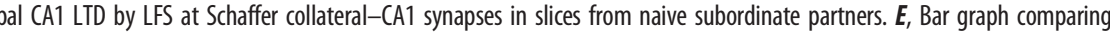
$* * p<0.01$ compared with no LTD partner mice by two-tailed unpaired Student's $t$ test. stressed dominant mice (LTD, $n=5$; no LTD, $n=6 ; t_{(9)}=1.26$, $p=0.24$, two-tailed unpaired Student's $t$ test; Fig. $4 E)$. However, there was a significantly higher level of corticosterone in LTDexpressing subordinate naive partners than no LTD-expressing subordinate naive partners (LTD, $n=5$; no LTD, $n=6 ; t_{(9)}=$ 4.49, $p=0.002$, two-tailed unpaired Student's $t$ test; Fig. $4 E$ ). Our observations demonstrate that, in a male-male dyad, stress transmission happened in $\sim 45 \%$ of subordinate naive partners and stress buffering occurred in nearly $55 \%$ of stressed dominant mice (Fig. $4 F$ ).

Social behaviors are required for transmission and buffering of hippocampal metaplasticity after stress

We next explore how the transmission and buffering occur between stressed subjects and naive partners by quantifying interactive behaviors between pairs in their home cage during a $30 \mathrm{~min}$ period. We were able to identify 11 types of behaviors 
A
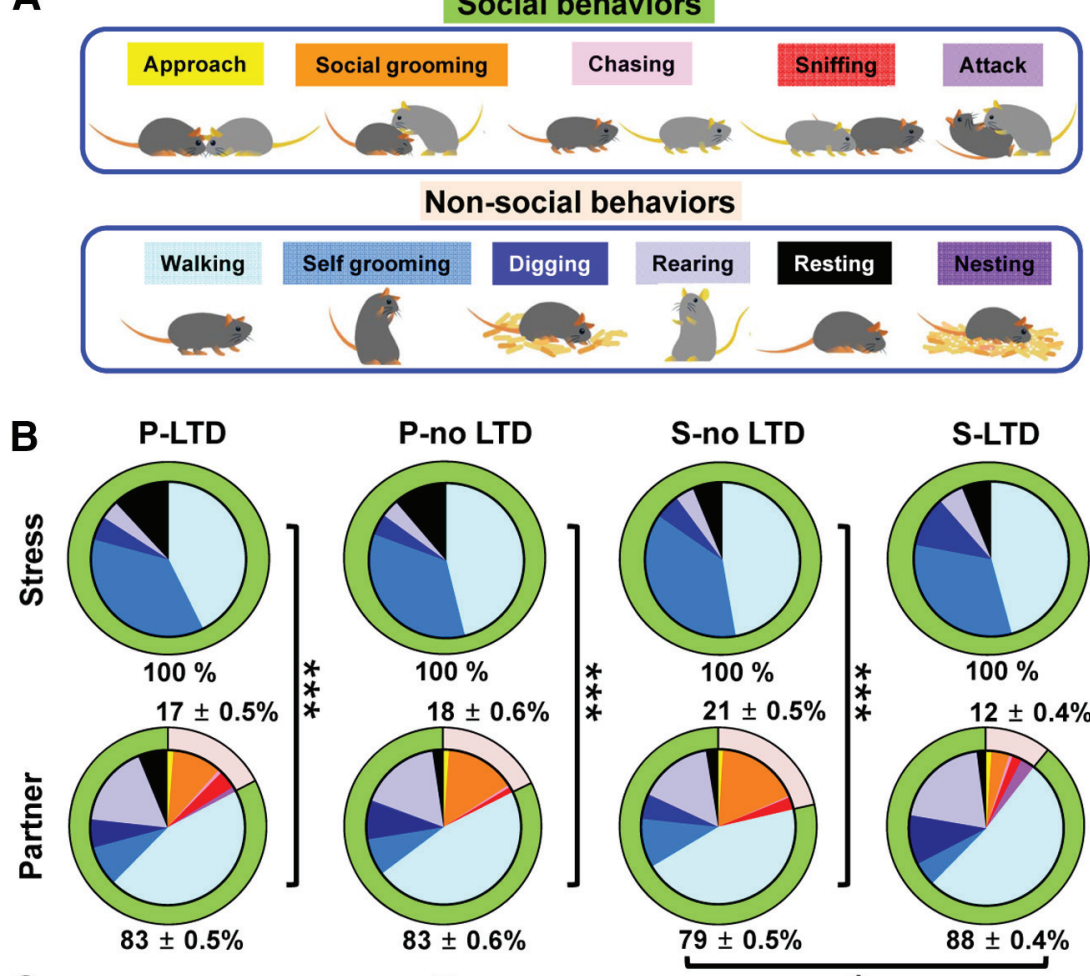

S-no LTD

D

C

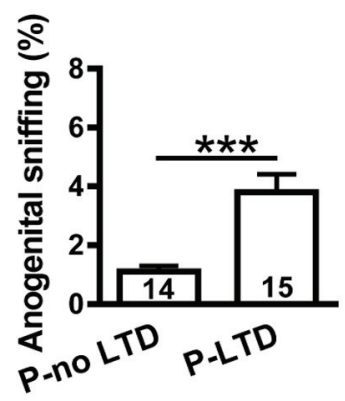

Figure 5. Transmission and buffering of metaplastic LTD require investigative behavior. A, Schematic showing 11 types of behaviors that include both social (approach, social grooming, chasing, sniffing, and attacking) and nonsocial behaviors (walking, self-grooming, digging, rearing, resting, and nesting). $\boldsymbol{B}$, Pie chart analysis of social and nonsocial behaviors of mouse dyads in 30 min epochs in home cage. $* p<0.05$ and $* * * p<0.001$ by $\chi^{2}$ test. $C$, Bar graph comparing the percentage of time spent in social grooming behavior toward stressed mice with or without LTD induction. $D$, Bar graph comparing the percentage of time engaged in anogenital sniffing behavior in naive partners with or without LTD induction. Data represent the mean \pm SEM. Numbers in parenthesis represent animals examined. $* * p<0.01, * * * p<0.001$ compared with no LTDexpressing mice by two-tailed unpaired Student's $t$ test.

that include both social [approach, social grooming (allogrooming), chasing, sniffing, and attacking] and nonsocial behavior (walking, self-grooming, digging, rearing, resting, and nesting; Fig. 5A). While seven behaviors were observed, there were a number of differences between stressed subjects and naive partners. Notably, stressed subjects spent their time mostly in walking, self-grooming, digging, rearing, and resting, whereas naive partners performed more interactive behaviors, such as sniffing, chasing, and allogrooming. Conversely, partners spent significantly more time engaged in social behaviors $\left(p<0.001, \chi^{2}\right.$ test; Fig. $5 B$ ). In pairing with stressed subjects, naive partners performed more social behaviors in pairing with no-LTD stressed subjects than in pairing with LTD-expressing stressed subjects $\left(p=0.03, \chi^{2}\right.$ test; Fig. 5B). Since previous work has shown that anogenital sniffing (snout toward the anogenital area of a partner) and social grooming (grooming directed to a partner) are potential behavioral mechanisms underlying the communication of stress-related information between animals (Sterley et al., 2018), these two interactive behaviors could potentially account for the transmission and buffering of hippocampal metaplasticity after stress. To test this possibility, we assessed the impact of social grooming on social buffering of stress and of anogenital sniffing on social transmission of stress. The amount of social grooming in no LTDexpressing stressed subjects was significantly higher than that in LTD-expressing stressed subjects (LTD, $n=9$; no LTD, $n=11 ; t_{(18)}=3.63, p=0.002$, twotailed unpaired Student's $t$ test; Fig. 5C). In addition, LTD-expressing naive partners spent more time engaged in anogenital sniffing than did no LTD-expressing naive partners (LTD, $n=15$; no LTD, $n=14$; $t_{(27)}=4.09, p=0.0003$, two-tailed unpaired Student's $t$ test; Fig. 5D). These results suggest that investigative behaviors involving direct contact are required for transmission and buffering occurred between stressed subjects and naive partners.

To further establish the link between investigative behaviors and social transmission of stress-induced metaplasticity, a stressed subject was separated, with a naive partner using a transparent perforated Plexiglas barrier during the period of social interactions (Fig. 6A). We found that LTD was evident in slices from all stressed mice $(29.8 \pm 3.5 \%, n=7$; Fig. $6 B)$, whereas no reliable LTD was observed in slices from naive partners (5.8 $\pm 4.9 \%, n=7 ; p=0.001$, between stressed mice and naive partners, MannWhitney $U$ test; Fig. $6 C$ ). In addition, stressed mice separated from partners by Plexiglas barrier showed an increase in corticosterone levels; however, naive partners failed to mount a corticosterone response (stress, $n=7$; partner, $n=7$; $t_{(12)}=4.59, p<0.001$, two-tailed unpaired Student's $t$ test; Fig. $6 D$ ). Our observations demonstrate that neither stress transmission nor stress buffering occurred between stressed subjects and naive partners with a barrier to prevent direct physical contact during social interactions (Fig. 6E).

Given the above results implicating a significant role of anogenital sniffing in social transmission of stress from stressed subjects to naive partner, we reasoned that alarm pheromones released from the anogenital area of stressed subjects lead to transmitted stress (Kiyokawa et al., 2004; Inagaki et al., 2009). To test this prediction, we used dichlobenil to chemically ablate the olfactory epithelium of naive partners (Fig. 7A; Lazarini et al., 2012). We conducted olfactory preference test to confirm the effectiveness of sensory deafferentation in dichlobenil-treated mice. We measured the total time spent investigating the filter papers scented with peanut butter and water. Control mice spent 
significantly more time in sniffing the filter paper scented with peanut butter than the filter paper scented with distilled water. Conversely, dichlobeniltreated mice showed no significantly greater attraction to peanut butter than to distilled water. A significant difference was observed between control and dichlobenil-treated mice in total exploratory time spent with the peanut butter subtracted from the time spent with water (control, $n=5$; dichlobenil treated, $n=5 ; t_{(8)}=4.51, p=0.002$, two-tailed unpaired Student's $t$ test; Fig. $7 B$ ). We also evaluated the effectiveness of this chemical ablation by quantifying immunostaining for OMP in the glomerular layer of the OB. In agreement with published reports (Yoon et al., 2005; Lazarini et al., 2012), we observed a drastic decrease in the OMP immunoreactivity following administration of dichlobenil (Fig. 7C). No significant difference was observed between vehicleand dichlobenil-treated mice in locomotor activity assessed by an open field test (data not shown). To evaluate social transmission and buffering after stress, a control mouse was subjected to stress and a dichlobenil-treated mouse was assigned as a naive partner. We found that LTD was evident in slices from all stressed mice ( $41.3 \pm 4.8 \%, n=5$; Fig. $7 D)$, whereas we failed to find reliable LTD in slices from dichlobenil-treated naive partners $(1.2 \pm 4.8 \%, n=5$; $p=0.001$ between stressed mice and naive partners, Mann-Whitney $U$ test; Fig. 7E). In addition, stressed mice showed an increase in corticosterone levels; however, dichlobenil-treated naive partners failed to mount a corticosterone response (stressed mice, $n=5$; partners, $n=5 ; t_{(8)}=$ 9.69, $p<0.001$, two-tailed unpaired Student's $t$ test; Fig. $7 F$ ). Our observations demonstrate that neither stress transmission nor stress buffering occurred between stressed subjects and dichlobeniltreated naive partners (Fig. 7G).

The requirement of corticosterone for stress-induced LTD induction in subjects and partners

Next, we determined whether the facilitation of LTD by authentic stress and by transmitted stress relies on the same neurobiological mechanisms. Previous work from our laboratory has shown that corticosterone mediates the facilitation of LTD after acute stress in rats (Yang et al., 2004, 2005). To assess the role of corticosterone in authentic stress- and transmitted stress-mediated effects, we performed the experiments in male mice that received bilateral ADX (Fig. $8 A$ ). In the first experiment (group I), a control mouse was subjected to stress and an ADX mouse was assigned as a naive partner to determine whether corticosterone is necessary for transmitted stress-mediated LTD. ADX administered in a naive partner had no effects on allogrooming $(2.9 \pm 1.0 \%, n=5$; Fig. $8 B)$ or anogenital sniffing behavior ( $1.2 \pm 0.3 \%, n=5$; Fig. $8 C)$, compared with LTDexpressing stressed mice $\left(3.9 \pm 0.7 \%, n=9 ; t_{(12)}=0.79, p=0.44\right.$, two-tailed unpaired Student's $t$ test) and no LTD-expressing naive partners $\left(1.1 \pm 0.2 \%, n=14 ; t_{(17)}=0.21, p=0.84\right.$, two-tailed
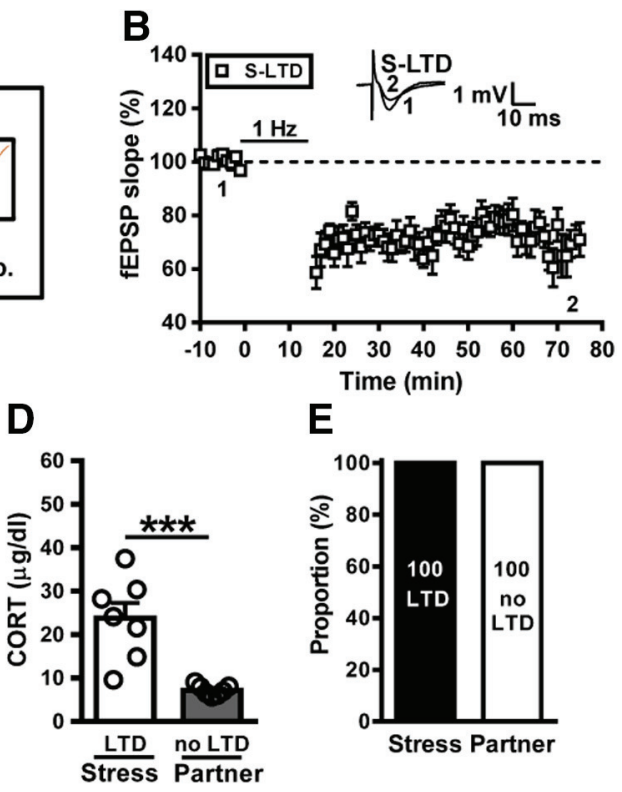

Figure 6. Direct behavioral contact is required for transmission and buffering of metaplastic LTD. $\boldsymbol{A}$, Schematic showexperimental design and timeline. In the experiment, the subject mouse was removed, exposed to a restraintdirect behavioral contact for $30 \mathrm{~min}$. B Summary of experiments showing the induction of hippocampal CA1 LTD by LFS at Schaffer collateral-CA1 synapses in slices from stressed mice. $\boldsymbol{C}$, Summary of experiments showing the induction of hippocampal CA1 LTD by LFS at Schaffer collateral-CA1 synapses in slices from naive partners. $\boldsymbol{D}$, Bar graph comparing corticosterone levels in stressed mice and naive partners. $\boldsymbol{E}$, Bar graph illustrating the proportion of individuals ing time indicated by number. Dashed lines show the level of baseline. Data represent the mean \pm SEM. $* * * p<0.001$ compared with LTD-expressing stress mice by two-tailed unpaired Student's $t$ test.

unpaired Student's $t$ test), respectively. We found that LTD was evident in slices from $100 \%$ of stressed mice $(37.6 \pm 2.9 \%, n=5$; Fig. $8 D, J)$, whereas no reliable LTD was observed in slices from ADX-naive partners $(0.5 \pm 4.1 \%, n=5 ; p=0.008$ between stressed mice and naive partners, Mann-Whitney $U$ test; Fig. $8 E, J)$. In addition, stressed mice showed an increase in corticosterone levels; however, ADX-naive partners failed to mount a corticosterone response (stress, $n=5$; partner, $n=5 ; t_{(8)}=6.89$, $p<0.0001$, two-tailed unpaired Student's $t$ test; Fig. $8 K$ ). We next examined whether corticosterone is necessary for authentic stress-mediated LTD. For this purpose, an ADX mouse was subjected to stress and a control mouse was assigned as a naive partner (group II). ADX administration in stressed mice had no effects on allogrooming $(8.5 \pm 3.4 \%, n=5$; Fig. $8 B)$ or anogenital sniffing behavior $(0.8 \pm 0.2 \%, n=5$; Fig. $8 C)$, compared with LTD-expressing stressed mice $\left(3.9 \pm 0.7 \%, n=9 ; t_{(12)}=1.78\right.$, $p=0.10$, two-tailed unpaired Student's $t$ test) and no LTDexpressing naive partners $\left(1.1 \pm 0.2 \%, n=14 ; t_{(17)}=0.82\right.$, $p=0.42$, two-tailed unpaired Student's $t$ test), respectively. Consistent with our previous findings (Yang et al., 2004, 2005), we failed to observe LTD in slices from stressed ADX mice $(0.1 \pm 4.6 \%, n=5$; Fig. $8 F, J)$. We observed no reliable LTD in slices from naive partners $(2.2 \pm 3.1 \%, n=5 ; p=0.52$ between stressed mice and naive partners, Mann-Whitney $U$ test; Fig. $8 G$, $J)$. Neither stressed ADX mice nor naive partners showed an increase in serum corticosterone levels (stressed mice, $n=5$; partner, $n=5 ; t_{(8)}=0.76, p=0.47$, two-tailed unpaired Student's $t$ test; Fig. $8 K$ ). Finally, ADX mice were assigned as stressed subject and naive partner (group III). ADX administration in both stressed mice and naive partners had no effects on allogrooming $(5.5 \pm$ $2.5 \%, n=4$; Fig. $8 B)$ or anogenital sniffing behavior $(0.7 \pm 0.2 \%$, 
A

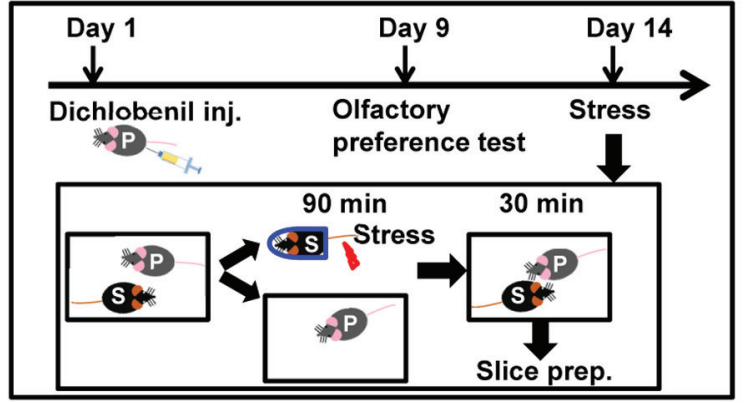

B

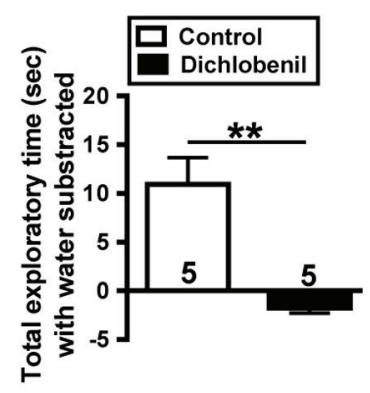

D

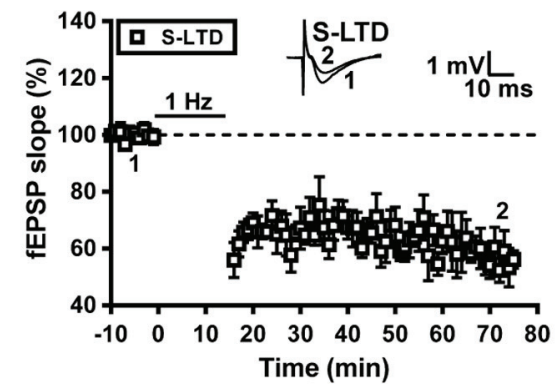

$\mathbf{F}$

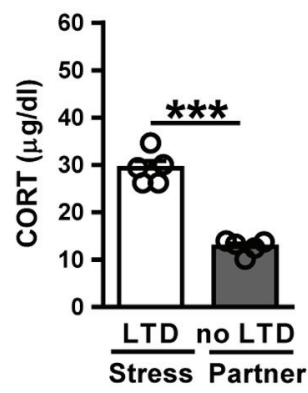

G

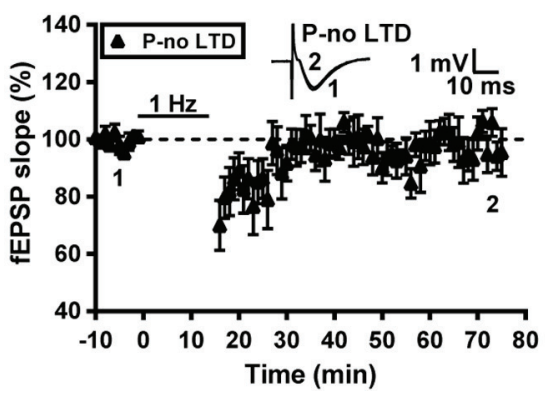

\section{Dichlobenil}

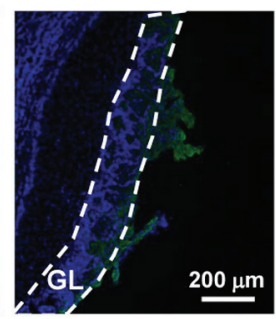

Figure 7. Chemical ablation of the olfactory epithelium of naive partners prevents the transmission of metaplastic LTD from stressed subjects to naive partners. $\boldsymbol{A}$, Schematic showing the experimental design and timeline. In the experiment, the partner mouse received dichlobenil $(150 \mathrm{mg} / \mathrm{kg})$ by intraperitoneal injection on day 1 and the olfactory preference test was used to assess of olfaction on day 9 . On day 14, the subject mouse was removed, exposed to a restraint-tailshock stress paradigm for $90 \mathrm{~min}$, and then returned to its home cage and allowed to freely interact with the dichlobenil-treated partner for $30 \mathrm{~min}$ before slice preparation. $\boldsymbol{B}$, Bar graph comparing the total exploratory time spent with the peanut butter subtracted from the time spent with distilled water in the olfactory preference test between control and dichlobenil-treated mice performed at day 9 after lesion. Numbers in parenthesis represent animals examined. C, Representative images of OMP immunostaining in the glomerular layer (GL) of the olfactory bulb of control and lesioned mice. Data were replicated in five mice of each group. $\boldsymbol{D}$, Summary of experiments showing the induction of hippocampal CA1 LTD by LFS at Schaffer collateral-CA1 synapses in slices from stressed mice. $\boldsymbol{E}$, Summary of experiments showing the induction of hippocampal CA1 LTD by LFS at Schaffer collateral-CA1 synapses in slices from naive partners. $\boldsymbol{F}$, Bar graph comparing serum corticosterone levels in stressed mice and naive partners. G, Bar graph illustrating the proportion of individuals that express LTD or no LTD in stressed and naive partner groups. Representative traces of fEPSPs were taken at the time indicated by number. Dashed lines show the level of baseline. Data represent the mean \pm SEM. $* * p<0.01, * * * p<0.001$ compared with control or LTD-expressing stress mice by two-tailed unpaired Student's $t$ test.

$n=4$; Fig. $8 C$ ), compared with LTD-expressing stressed mice (3.9 $\pm 0.7 \%, n=9 ; t_{(11)}=0.86, p=0.41$, two-tailed unpaired Student's $t$ test) and no LTD-expressing naive partners $(1.1 \pm$ $0.2 \%, n=14 ; t_{(16)}=1.07, p=0.31$, two-tailed unpaired Student's $t$ test), respectively. We failed to observe LTD in slices from either stressed ADX mice $(0.7 \pm 4.8 \%, n=4$; Fig. $8 H, J)$ or ADX-naive partners $(1.9 \pm 3.2 \%, n=4 ; p=0.87$ between stressed mice and naive partners, Mann-Whitney $U$ test; Fig. 8I,J). Neither stressed ADX mice nor naive partners showed an increase in serum corticosterone levels (stressed mice, $n=4$; partner, $n=4 ; t_{(6)}=2.43$,

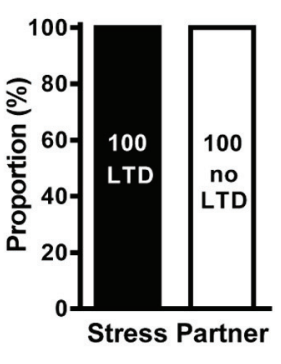

$p=0.06$, two-tailed unpaired Student's $t$ test; Fig. $8 K$ ). Our observations demonstrate that neither stress transmission nor stress buffering occurred between stressed ADX mice and naive partners (Fig. $8 L$ ). Collectively, these results suggest that corticosterone is necessary for the facilitation of LTD by authentic and transmitted stress.

We further asked whether LTD plays a role in social transmission of stress. Previous work from our laboratory has shown that pharmacological blockade of NMDA receptors during stress can prevent stress-induced facilitation of LTD induction in rats without affecting stressinduced elevation in plasma corticosterone (Yang et al., 2008). Therefore, we test whether prevention of LTD by NMDA receptor antagonist in stressed mice may influence the induction of LTD in naive partners. To this end, we bilaterally injected the subjects with a NMDA receptor antagonist APV (3.2 $\mu \mathrm{g}, 0.5 \mu \mathrm{l} /$ side) into the CA1 region of the hippocampus, $20 \mathrm{~min}$ before stress. In the control group, the subjects received vehicle injections before stress (Fig. 9A). When comparing the grand mean LTD magnitudes, no significant difference was observed between vehicle-treated stressed subjects $(11.2 \pm 3.1 \%, n=10)$ and naive partners $(12.0 \pm 2.8 \%, n=10$; $p=0.89$, Mann-Whitney $U$ test; Fig. $9 B)$. We found that NMDA receptor antagonism in stressed subjects blocked LTD induction; however, significant LTD was induced in slices from some naive partners (Fig. 9C). When comparing the grand mean LTD magnitudes, there was a trend of difference between APV-treated stressed subjects (2.2 \pm $1.5 \%, n=11)$ and naive partners (9.8 \pm $3.2 \%, n=11 ; p=0.08$, Mann-Whitney $U$ test; Fig. 9C). Across the population $(n=10)$, we observed that a subpopulation of vehicle-treated stressed subjects $(n=6 / 10)$ displayed obvious LTD (17.1 \pm $3.2 \%)$, whereas a subpopulation of stressed subjects $(n=4 / 10)$ showed no LTD $(2.4 \pm 1.3 \%$; Fig. 9D). In pairing with vehicle-treated stressed subjects, we found that LTD $(21.3 \pm 1.9 \%)$ was evident in slices from $40 \%(n=4 / 10)$ naive partners (Fig. 9E). In pairing with APVtreated stressed subjects, we observed that a subpopulation of naive partners $(n=5 / 11)$ displayed obvious LTD $(19.0 \pm 3.2 \%)$, whereas a subpopulation of naive partners $(n=6 / 11)$ showed no LTD $(0.8 \pm 1.8 \%$; Fig. $9 F)$. Our observations demonstrate that stress transmission happened in $\sim 40 \%$ of naive partners in pairing with vehicle-treated stressed subjects and in nearly $45 \%$ of naive partners in pairing with APV-treated stressed subjects $(p=0.47$, $\chi^{2}$ test; Fig. 9G). These observations demonstrate that LTD does not affect social transmission of stress. 
A

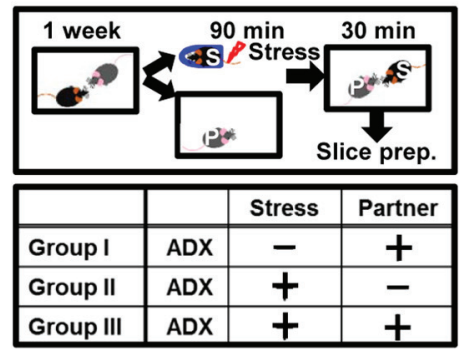

D

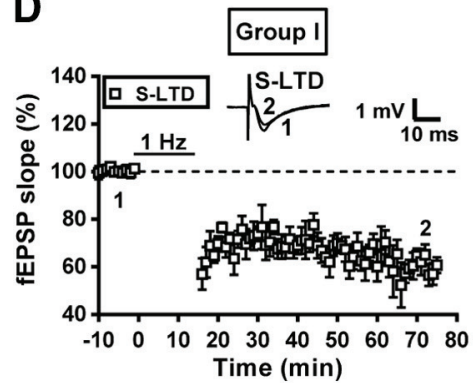

G

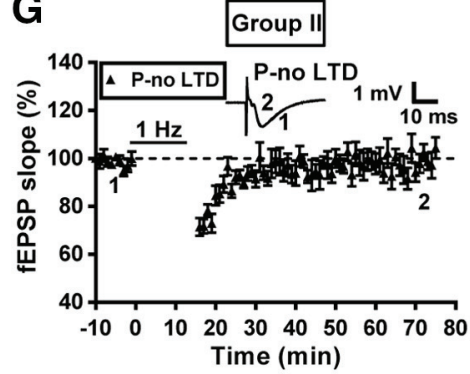

J

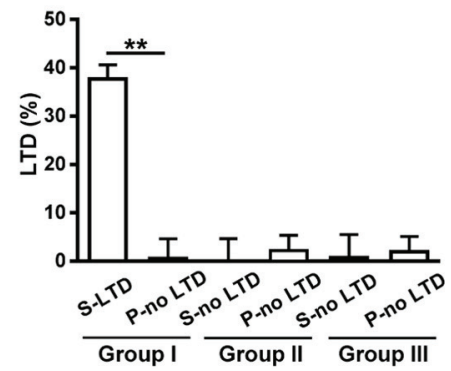

B

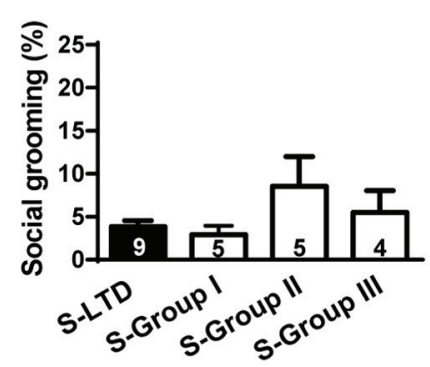

E

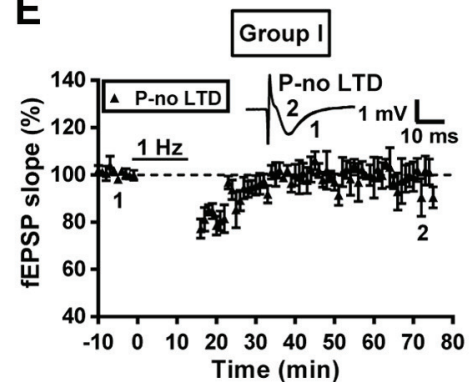

H Group III

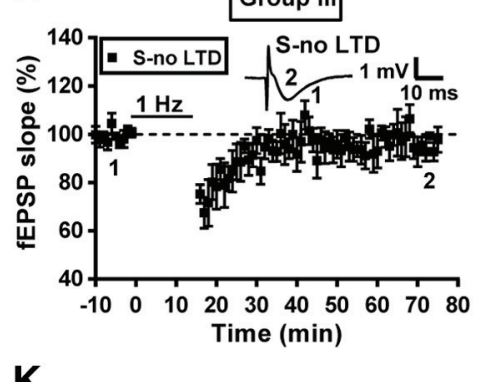

K

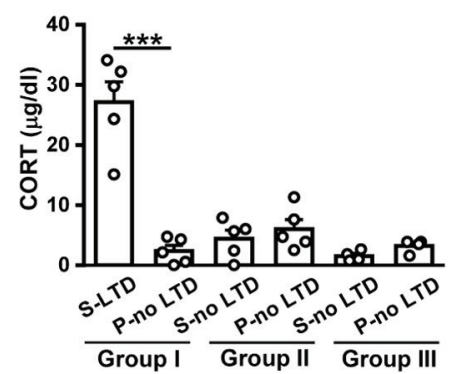

C

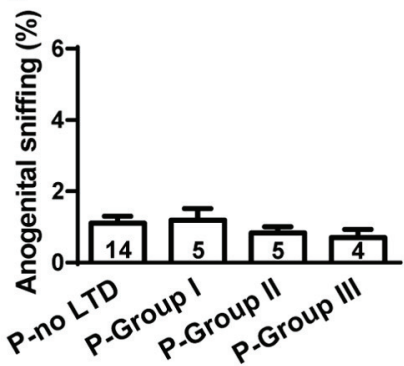

F

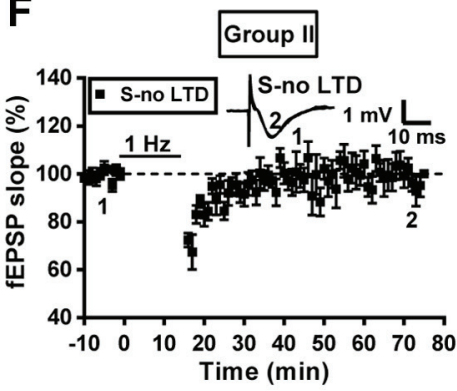

I Group III

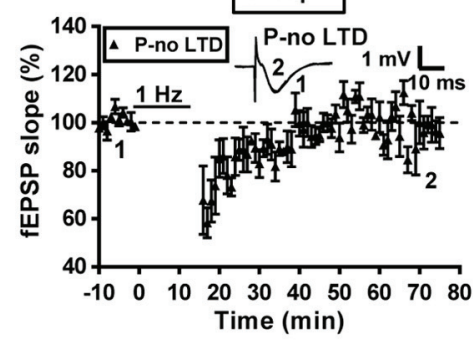

L

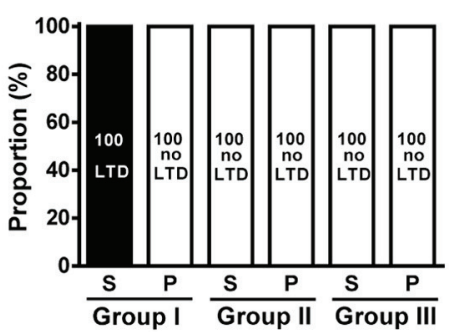

Figure 8. Adrenalectomy prevents metaplastic LTD in both stressed subjects and naive partners. $\boldsymbol{A}$, Schematic illustration of the experimental design. $\boldsymbol{B}$, Bar graph comparing the percentage of time spent in social grooming behavior in stressed subjects and naive partners with or without ADX. C, Bar graph comparing the percentage of time engaged in anogenital sniffing behavior in stressed subjects and naive partners with or without ADX. D, Summary of experiments showing the induction of hippocampal CA1 LTD by LFS at Schaffer collateral-CA1 synapses in slices from stressed mice. $\boldsymbol{E}$, Summary of experiments showing the induction of hippocampal CA1 LTD by LFS at Schaffer collateral-CA1 synapses in slices from ADX-naive partners. $\boldsymbol{F}$, Summary of experiments showing the induction of hippocampal CA1 LTD by LFS at Schaffer collateral-CA1 synapses in slices from ADX stressed mice. G, Summary of experiments showing the induction of hippocampal CA1 LTD by LFS at Schaffer collateral-CA1 synapses in slices from naive partners. $\boldsymbol{H}$, Summary of experiments showing the induction of hippocampal CA1 LTD by LFS at Schaffer collateral-CA1 synapses in slices from ADX stressed mice. I, Summary of experiments showing the induction of hippocampal CA1 LTD by LFS at Schaffer collateral-CA1 synapses in slices from ADX-naive partners. J, Bar graphs comparing the average magnitudes of LTD in slices from stressed mice and naive partners with or without ADX. $\boldsymbol{K}$, Bar graph comparing serum corticosterone levels in stressed mice and naive partners with or without ADX. L, Bar graph illustrating the proportion of individuals that express LTD or no LTD in stressed and naive partner groups with or without ADX. Representative traces of fEPSPs were taken at the time indicated by number. Dash lines show the level of baseline. Data represent the mean \pm SEM. Numbers in parentheses represent the animals examined. $* * p<0.01$ and $* * * p<0.001$ compared with no LTD-expressing partner mice by Mann-Whitney $U$ test or two-tailed unpaired Student's $t$ test.

\section{Discussion}

Social species can acquire information about their environment through conspecific interactions. The transmission and buffering of stress responses between conspecifics are broadly observed and highly conserved phenomena (Gunnar et al., 2015; de Waal and Preston, 2017; Debiec and Olsson, 2017; Oliveira and
Faustino, 2017; Kiyokawa et al., 2018; Monfils and Agee, 2019). Stress can trigger enduring changes in the ability of synapses to exhibit synaptic plasticity, resulting in metaplasticity (Kim and Diamond, 2002; Huang et al., 2005; Schmidt et al., 2013). While numerous studies have documented that the behavioral and hormone responses of stress can be transmitted to naive individuals, 
A

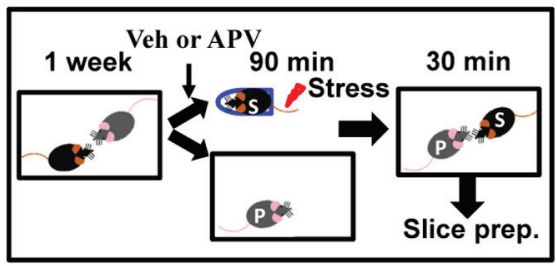

C

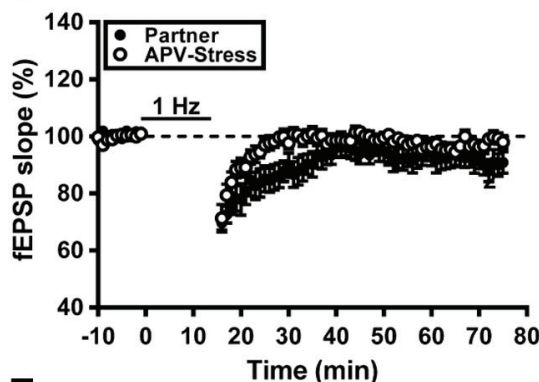

E

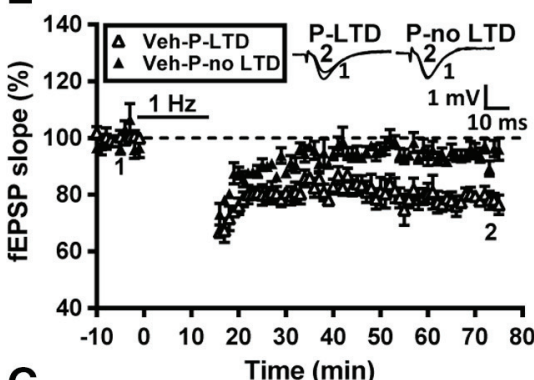

G

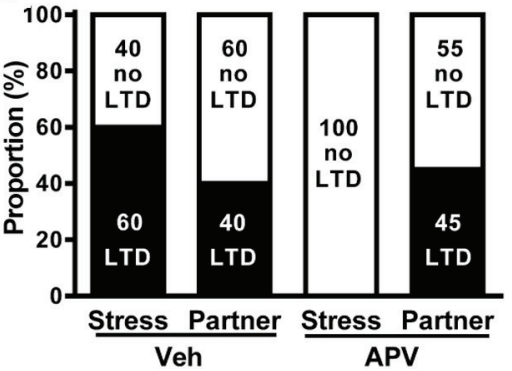

B
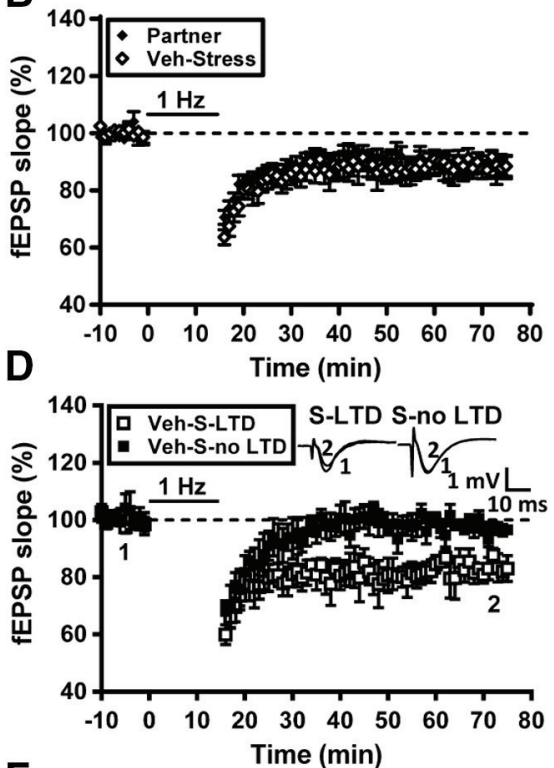

F

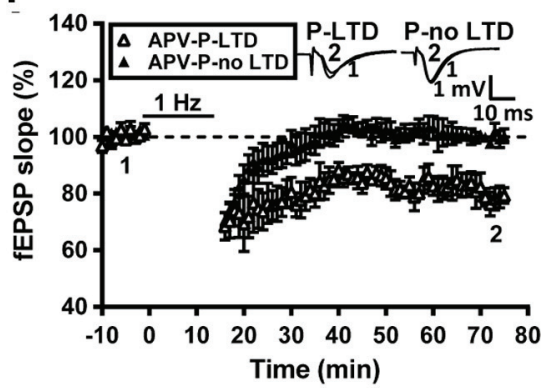

following social interactions with naive partners. Hierarchical status affects the vulnerability to social buffering of stress effects. In particular, we found that investigative behaviors involving direct contacts are essential for the emergence of transmission and buffering of stressinduced metaplasticity.

Very little is known about the synaptic consequences of transmitted stress. An earlier study using acute footshock stress has shown that authentic and transmitted stress primed glutamatergic synapses onto PVN CRH neurons to induce STP (Sterley et al., 2018). Our results complement these findings by showing that transmission and buffering of synaptic changes after stress are also evident at hippocampal CA1 synapses. Our data, however, suggest a slightly more complicated scenario than previously thought (Sterley et al., 2018). We provide novel evidence that heterogeneity exists across individuals in vulnerability to synaptic consequences of social transmission and buffering of stress. Notably, only a portion of naive partners expressed transmitted stress in the pairs with stressed subjects. Such individual differences may be partly attributed to different levels of social interactions between stressed subjects and partners. Regardless of individual differences, we found that transmitted stress triggers enduring hippocampal metaplasticity in exactly the same way as authentic stress. This notion is supported by the observation that LTD was significantly reduced in slices from stressed subjects and partners receiving ADX, implying that corticosterone is necessary for stress-induced facilitation of LTD (Fig. 8). In agreement with this, we have found that authentic and transmitted stress resulted in increased serum corticosterone levels. Elevated circulating corticosterone levels, which dampen the glutamate uptake by activating glucocorticoid receptors, have been identified as a prominent mechanism underlying stressinduced facilitation of LTD in hippocampal CA1 region (Yang et al., 2004, 2005). Our results demonstrate that the basal glutamatergic synaptic transmission was not altered by acute stress (Fig. 1C). This finding seems inconsistent with observations made in a previous study, which reported that corticosterone can rap-

this study provides the first demonstration that male mice rely on social interactions with others to transmit stress-induced hippocampal metaplasticity from stressed subjects to partners. We have demonstrated that both authentic and transmitted stress prime glutamatergic synapses onto hippocampal CA1 neurons to undergo LTD. This hippocampal metaplasticity is bufferable idly tune synaptic NMDA receptor through membrane dynamics (Mikasova et al., 2017). The cause of this inconsistency across studies is unclear, but it may be related to the use of different systems (in vivo animal model vs in vitro hippocampal cultures). Our findings are consistent with those of a previous 
study showing lack of effect of acute stress on the synaptic input-output relationship in the CA1 region of rat hippocampus (Chaouloff et al., 2007). It is noteworthy that the synaptic mechanism underlying authentic or transmitted stressinduced priming of glutamatergic synapses onto PVN CRH neurons to express STP, as found in the study by Sterley et al. (2018), required CRHR1 activity. This discrepancy could be caused by the distinct types of metaplasticity (LTD vs STP) and brain regions (hippocampus vs PVN) examined among studies.

Animals can convey information about their emotional state through chemosignals, ultrasonic vocalizations, and overt changes in behaviors (Zalaquett and Thiessen, 1991; Sotocinal et al., 2011; Brudzynski, 2013). Previous studies have documented that stressed animals can release social pheromones from the anal glands to alarm or attract nearby conspecifics (Kiyokawa et al., 2006, 2013; Kiyokawa, 2017). Although we did not identify the specificity of alarm pheromones, they are likewise critical for the social transmission of stress-induced hippocampal metaplasticity from stressed subjects to partners. Three main findings support this notion. First, partners that spend more time engaged in sniffing toward the anogenital region of stressed subjects showed reliable LTD (Fig. 5). Such directional sniffing behavior toward stressed conspecifics has been reported previously (Bruchey et al., 2010; Knapska et al., 2010; Sterley et al., 2018). Second, hippocampal slices from partners physically separated from stressed subjects during social interaction failed to induce LTD (Fig. 6). Third, chemical ablation of the olfactory epithelium in partners with dichlobenil blocked sniffing behavior toward stressed subjects and failed to show reliable LTD (Fig. 7). Our results also demonstrate that social buffering effect by partners is related to allogrooming behavior toward stressed subjects. Indeed, LTD was not reliably induced in slices from stressed subjects that received more allogrooming from partners. This observation is consistent with the view that more social contact may provide the chemosensory or somatosensory cues to evoke hypothalamic oxytocin release in the promotion of social buffering of stress responses (Smith and Wang, 2014).

Social interactions between individuals are not equal and could be influenced by dominant-subordinate relationships (Beery and Kaufer, 2015; Kingsbury et al., 2019). Our study suggests that the preexisting hierarchical status strongly affects vulnerability to social buffering effects. Interestingly, we found that no stress buffering occurred in stressed subordinate mice when paired with their naive dominant partners. By contrast, social buffering is evident in stressed dominant mice in the pairs with naive subordinate partners. These findings are consistent with previous work suggesting that socially dominant male C57BL/6 mice engage in more social interactions with conspecifics compared with subordinate male mice (Kunkel and Wang, 2018). While we cannot exclude the involvement of other prosocial behaviors in mediating social buffering, our finding supports allogrooming as the predominant neurobehavioral mechanism underpinning this social process. We confirmed that subordinate naive partners engaged in less social grooming behavior than dominant naive partners toward their respective stressed subjects. Indeed, allogrooming is often interpreted as an affiliative function promoting positive social relationships and reducing perceived stress (Clark and Schein, 1966; McFarlane et al., 2008). Nonetheless, the vulnerability to social transmission of stress was not significantly affected by the dominant-subordinate relationship between stressed subjects and naive partners. Thus, social transmission and buffering of stress responses cannot simply be viewed as complementary social processes. Although insufficient data are available to completely support this notion, we observed that social transmission and buffering of hippocampal metaplasticity after stress can occur independently of each other in a male-male dyad.

It remains unclear whether there are sex differences in vulnerability to social transmission and buffering of stress. Interestingly, Sterley et al. (2018) demonstrate that social buffering is more effective in females than males. Since both authentic and transmitted stress were unable to induce reliable LTD at hippocampal CA1 synapses of female mice, this form of metaplasticity is not appropriate to address this issue. Although the exact cause of this sex bias remain unclear, previous work in our laboratory has demonstrated that the organizational effect of testosterone on brain development at birth is important for the expression of this sexual dimorphism (Huang et al., 2012). Further studies are needed to clarify this issue.

Metaplasticity serves to maintain synaptic function within a dynamic range of modifiability, and the neural network at an appropriate level for information processing and storage (Abraham, 2008; Schmidt et al., 2013). An important question concerns the possible behavioral consequences of transmitted metaplasticity. Considering that stress-induced facilitation of LTD may adjust output plasticity through synchronized spikes and spontaneous unitary discharges to other brain structures under stressful conditions (Cao et al., 2004), it is likely that transmitted LTD may contribute to the storage of information about stressful events. Thus, it is reasonable to speculate that social animals may use this transmitted metaplasticity to edit their neural networks to prepare adequately for coping with stress exposure without costly first-hand experience of threats (Sterley et al., 2018). The facilitation of LTD by stress can also be interpreted as a direct modulation of LTD induction mechanisms. Previous studies have provided evidence that stress and corticosterone can enhance L-type $\mathrm{Ca}^{2+}$ channel currents (Mamczarz et al., 1999; Chameau et al., 2007) and that hippocampal CA1 LTD can be blocked by the inhibition of L-type $\mathrm{Ca}^{2+}$ channels (Niehusmann et al., 2010; Normann et al., 2018). It will be interesting to test whether a direct modulation of $\mathrm{Ca}^{2+}$ channels by corticosterone is involved in stressinduced facilitation of LTD.

In conclusion, we provide evidence that stress enables the induction of metaplasticity at hippocampal CA1 synapses and that such stress-induced hippocampal metaplasticity can be transmitted from stressed subjects to naive partners via social interactions in a male-male dyad. The presence of naive partners can provide social buffering of synaptic consequences after stress. Unraveling the factors that confer the transmission and buffering of synaptic changes of stress may offer an opportunity to develop novel therapeutic strategies for treatment of stress-related psychiatric disorders, especially anxiety and depression symptoms, after learning about traumatic experiences from others.

\section{References}

Abraham WC (2008) Metaplasticity: tuning synapses and networks for plasticity. Nat Rev Neurosci 9:387.

Beery AK, Kaufer D (2015) Stress, social behavior, and resilience: insights from rodents. Neurobiol Stress 1:116-127. 
Bruchey AK, Jones CE, Monfils MH (2010) Fear conditioning by-proxy: social transmission of fear during memory retrieval. Behav Brain Res 214:80-84.

Brudzynski SM (2013) Ethotransmission: communication of emotional states through ultrasonic vocalization in rats. Curr Opin Neurobiol 23:310-317.

Burkett JP, Andari E, Johnson ZV, Curry DC, de Waal FB, Young LJ (2016) Oxytocin-dependent consolation behavior in rodents. Science 351:375-378.

de Waal FBM, Preston SD (2017) Mammalian empathy: behavioural manifestations and neural basis. Nat Rev Neurosci 18:498-509.

Cao J, Chen N, Xu T, Xu L (2004) Stress-facilitated LTD induces output plasticity through synchronized-spikes and spontaneous unitary discharges in the CA1 region of the hippocampus. Neurosci Res 49:229-239.

Chameau P, Qin Y, Spijker S, Smit AB, Smit G, Joëls M (2007) Glucocorticoids specifically enhance L-type calcium current amplitude and affect calcium channel subunit expression in the mouse hippocampus. J Neurophysiol 97:5-14.

Chaouloff F, Hémar A, Manzoni O (2007) Acute stress facilitates hippocampal CA1 metabotropic glutamate receptor-dependent long-term depression. J Neurosci 27:7130-7135.

Chen CC, Yang CH, Huang CC, Hsu KS (2010) Acute stress impairs hippocampal mossy fiber-CA3 long-term potentiation by enhancing cAMP-specific phosphodiesterase 4 activity. Neuropsychopharmacology 35:1605-1617.

Clark LH, Schein MW (1966) Activities associated with conflict behaviour in mice. Anim Behav 14:44-49.

Debiec J, Olsson A (2017) Social fear learning: from animal models to human function. Trends Cogn Sci 21:546-555.

Diamond DM, Bennett MC, Fleshner M, Rose GM (1992) Inverted-U relationship between the level of peripheral corticosterone and the magnitude of hippocampal primed burst potentiation. Hippocampus 2:421-430.

Gunnar MR, Hostinar CE, Sanchez MM, Tottenham N, Sullivan RM (2015) Parental buffering of fear and stress neurobiology: reviewing parallels across rodent, monkey, and human models. Soc Neurosci 10:474-478.

Franklin K, Paxinos G (2008) The mouse brain in stereotaxic coordinates, Ed 3. San Diego: Elsevier Academic.

Hsiao YM, Tsai TC, Lin YT, Chen CC, Huang CC, Hsu KS (2016) Early life stress dampens stress responsiveness in adolescence: evaluation of neuroendocrine reactivity and coping behavior. Psychoneuroendocrinology 67:86-99.

Huang CC, Yang CH, Hsu KS (2005) Do stress and long-term potentiation share the same molecular mechanisms? Mol Neurobiol 32:223-235.

Huang CC, Chen JP, Yeh CM, Hsu KS (2012) Sex difference in stressinduced enhancement of hippocampal CA1 long-term depression during puberty. Hippocampus 22:1622-1634.

Inagaki H, Nakamura K, Kiyokawa Y, Kikusui T, Takeuchi Y, Mori Y (2009) The volatility of an alarm pheromone in male rats. Physiol Behav 96:749-752.

Khoo GH, Lin YT, Tsai TC, Hsu KS (2019) Perineuronal nets restrict the induction of long-term depression in the mouse hippocampal CA1 region. Mol Neurobiol 56:6436-6450.

Kim JJ, Diamond DM (2002) The stressed hippocampus, synaptic plasticity and lost memories. Nat Rev Neurosci 3:453-462.

Kim JJ, Foy MR, Thompson RF (1996) Behavioral stress modifies hippocampal plasticity through N-methyl-D-aspartate receptor activation. Proc Natl Acad Sci U S A 93:4750-4753.

Kingsbury L, Huang S, Wang J, Gu K, Golshani P, Wu YE, Hong W (2019) Correlated neural activity and encoding of behavior across brains of socially interacting animals. Cell 178:429-446.

Kiyokawa Y (2017) Social odors: alarm pheromones and social buffering. Curr Top Behav Neurosci 30:47-65.

Kiyokawa Y, Kikusui T, Takeuchi Y, Mori Y (2004) Alarm pheromones with different functions are released from different regions of the body surface of male rats. Chem Senses 29:35-40.

Kiyokawa Y, Shimozuru M, Kikusui T, Takeuchi Y, Mori Y (2006) Alarm pheromone increases defensive and risk assessment behaviors in male rats. Physiol Behav 87:383-387.

Kiyokawa Y, Kodama Y, Kubota T, Takeuchi Y, Mori Y (2013) Alarm pheromone is detected by the vomeronasal organ in male rats. Chem Senses 38:661-668.

Kiyokawa Y, Kawai K, Takeuchi Y (2018) The benefits of social buffering are maintained regardless of the stress level of the subject rat and enhanced by more conspecifics. Physiol Behav 194:177-183.
Knapska E, Mikosz M, Werka T, Maren S (2010) Social modulation of learning in rats. Learn Mem 17:35-42.

Kobayakawa K, Kobayakawa R, Matsumoto H, Oka Y, Imai T, Ikawa M, Okabe M, Ikeda T, Itohara S, Kikusui T, Mori K, Sakano H (2007) Innate versus learned odour processing in the mouse olfactory bulb. Nature 450:503-508.

Kunkel T, Wang H (2018) Socially dominant mice in C57BL6 background show increased social motivation. Behav Brain Res 336:173-176.

Larrieu T, Cherix A, Duque A, Rodrigues J, Lei H, Gruetter R, Sandi C (2017) Hierarchical status predicts behavioral vulnerability and nucleus accumbens metabolic profile following chronic social defeat stress. Curr Biol 27:2202-2210.

Lazarini F, Gabellec MM, Torquet N, Lledo PM (2012) Early activation of microglia triggers long-lasting impairment of adult neurogenesis in the olfactory bulb. J Neurosci 32:3652-3664.

Mamczarz J, Budziszewska B, Antkiewicz-Michaluk L, Vetulani J (1999) The $\mathrm{Ca}^{2+}$ channel blockade changes the behavioral and biochemical effects of immobilization stress. Neuropsychopharmacology 20:248-254.

Martin LJ, Hathaway G, Isbester K, Mirali S, Acland EL, Niederstrasser N, Slepian PM, Trost Z, Bartz JA, Sapolsky RM, Sternberg WF, Levitin DJ, Mogil JS (2015) Reducing social stress elicits emotional contagion of pain in mouse and human strangers. Curr Biol 25:326-332.

McFarlane HG, Kusek GK, Yang M, Phoenix JL, Bolivar VJ, Crawley JN (2008) Autism-like behavioral phenotypes in BTBR T+tf/J mice. Genes Brain Behav 7:152-163.

Mikasova L, Xiong H, Kerkhofs A, Bouchet D, Krugers HJ, Groc L (2017) Stress hormone rapidly tunes synaptic NMDA receptor through membrane dynamics and mineralocorticoid signaling. Sci Rep 7:8053.

Milner AJ, Cummings DM, Spencer JP, Murphy KP (2004) Bi-directional plasticity and age-dependent long-term depression at mouse CA3-CA1 hippocampal synapses. Neurosci Lett 367:1-5.

Monfils MH, Agee LA (2019) Insights from social transmission of information in rodents. Genes Brain Behav 18:e12534.

Niehusmann P, Seifert G, Clark K, Atas HC, Herpfer I, Fiebich B, Bischofberger J, Normann C (2010) Coincidence detection and stress modulation of spike time-dependent long-term depression in the hippocampus. J Neurosci 30:6225-6235.

Normann C, Frase S, Haug V, von Wolff G, Clark K, Münzer P, Dorner A, Scholliers J, Horn M, Vo Van T, Seifert G, Serchov T, Biber K, Nissen C, Klugbauer N, Bischofberger J (2018) Antidepressants rescue stressinduced disruption of synaptic plasticity via serotonin transporter-independent inhibition of L-type calcium channels. Biol Psychiatry 84:55-64.

Oliveira RF, Faustino AI (2017) Social information use in threat perception: social buffering, contagion and facilitation of alarm responses. Commun Integr Biol 10:e1325049.

Schmidt MV, Abraham WC, Maroun M, Stork O, Richter-Levin G (2013) Stress-induced metaplasticity: from synapses to behavior. Neuroscience 250:112-120.

Shors TJ, Gallegos RA, Breindl A (1997) Transient and persistent consequences of acute stress on long-term potentiation (LTP), synaptic efficacy, theta rhythms and bursts in area CA1 of the hippocampus. Synapse 26:209-217.

Smith AS, Wang Z (2014) Hypothalamic oxytocin mediates social buffering of the stress response. Biol Psychiatry 76:281-288.

Sotocinal SG, Sorge RE, Zaloum A, Tuttle AH, Martin LJ, Wieskopf JS, Mapplebeck JC, Wei P, Zhan S, Zhang S, McDougall JJ, King OD, Mogil JS (2011) The Rat Grimace Scale: a partially automated method for quantifying pain in the laboratory rat via facial expressions. Mol Pain 7:55.

Sterley TL, Baimoukhametova D, Füzesi T, Zurek AA, Daviu N, Rasiah NP, Rosenegger D, Bains JS (2018) Social transmission and buffering of synaptic changes after stress. Nat Neurosci 21:393-403.

Stiedl O, Birkenfeld K, Palve M, Spiess J (2000) Impairment of conditioned contextual fear of C57BL/6J mice by intracerebral injections of the NMDA receptor antagonist APV. Behav Brain Res 116:157-168.

Tsai TC, Huang CC, Hsu KS (2019) Infantile amnesia is related to developmental immaturity of the maintenance mechanisms for long-term potentiation. Mol Neurobiol 56:6436-6450. 
Wang F, Zhu J, Zhu H, Zhang Q, Lin Z, Hu H (2011) Bidirectional control of social hierarchy by synaptic efficacy in medial prefrontal cortex. Science 334:693-697.

Wang F, Kessels HW, Hu H (2014) The mouse that roared: neural mechanisms of social hierarchy. Trends Neurosci 37:674-682.

Williamson CM, Romeo RD, Curley JP (2017) Dynamic changes in social dominance and mPOA GnRH expression in male mice following social opportunity. Horm Behav 87:80-88.

Xu L, Anwyl R, Rowan MJ (1997) Behavioural stress facilitates the induction of long-term depression in the hippocampus. Nature 387:497-500.

Yang CH, Huang CC, Hsu KS (2004) Behavioral stress modifies hippocampal synaptic plasticity through corticosterone-induced sustained extracellular signal-regulated kinase/mitogen-activated protein kinase activation. J Neurosci 24:11029-11034.
Yang CH, Huang CC, Hsu KS (2005) Behavioral stress enhances hippocampal CA1 long-term depression through the blockade of the glutamate uptake. J Neurosci 25:4288-4293.

Yang CH, Huang CC, Hsu KS (2006) Novelty exploration elicits a reversal of acute stress-induced modulation of hippocampal synaptic plasticity in the rat. J Physiol 577:601-615.

Yang PC, Yang CH, Huang CC, Hsu KS (2008) Phosphatidylinositol 3 -kinase activation is required for stress protocol-induced modification of hippocampal synaptic plasticity. J Biol Chem 283:26312643.

Yoon H, Enquist LW, Dulac C (2005) Olfactory inputs to hypothalamic neurons controlling reproduction and fertility. Cell 123:669-682.

Zalaquett C, Thiessen D (1991) The effects of odors from stressed mice on conspecific behavior. Physiol Behav 50:221-227. 